\title{
Perception, career choice and self-efficacy of UK medical students and junior doctors in urology
}

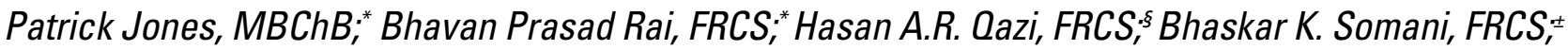 \\ Ghulam Nabi, FRCS*
}

*Department of Urology, Ninewells Hospital, Dundee, UK; §Gartnavel General Hospital, Glasgow, UK; 士University Hospital Southampton NHS Trust, Southampton UK.

Cite as: Can Urol Assoc J 2015;(9-10):E573-8. http://dx.doi.org/10.5489/cuaj.2919

Published online September 9, 2015.

\section{Abstract}

Introduction: There is a growing concern about the reduced clinical exposure to urology at undergraduate level in the United Kingdom. As a consequence, the competencies of junior doctors are considered inadequate. The views of these doctors in training towards urology remain under reported. Methods: A modified Delphi method was employed to construct a questionnaire. Given the rise of social media as a platform for scientific discussion, participants were recruited via a social networking site. Outcomes assessed included career preference, exposure to urology, perceived male dominance, and confidence at core procedures.

Results: In total, 412 and 66 responses were collected from medical students and junior doctors, respectively. Overall, $41 \%$ of participants felt that they had received a good level of clinical exposure to urology as part of their training and $15 \%$ were considering a career in this speciality. Female students were significantly less likely to consider urology as a career option $(p<0.01)$. Of these, $37 \%$ of the students felt confident at male catheterization and $46 \%$ of students regarded urology as a male-dominated speciality. Conclusions: Urology is perceived as male dominated and is the least likely surgical speciality to be pursued as a career option according to our survey. Increased exposure to urology at the undergraduate level and dedicated workshops for core urological procedures are needed to address these challenges.

\section{Introduction}

There is a growing concern about the reduced clinical exposure to urology at undergraduate level. ${ }^{1}$ There has been an inexorable decline in the clinical (basic surgical) rotations and clerkships that students now carry out in this surgical speciality. ${ }^{2}$ Indeed, it is a cause for worry, which has been increasingly realized in the United Kingdom. The resultant lack of core speciality specific knowledge affects the com- petencies of junior doctors' clinical practice. This has been observed in their low level of confidence and preparedness at core skills, such as urethral catheterization and at managing common urological presentations. ${ }^{3}$ At the same time, there is a growing incidence of urological pathologies presenting to both primary and secondary care services. ${ }^{4}$ There is a lack of formal research addressing these issues. Equally, the views of medical students towards urology remain under reported in the United Kingdom.

The objective of this study was to seek the views of medical students and junior doctors in the United Kingdom on the status of medical education in urology through a validated questionnaire using social media.

\section{Methods}

A modified Delphi technique was used to aggregate the survey questionnaire data and ensure content validity. Accordingly, an expert panel of 4 senior surgeons actively involved and experienced in medical education was recruited. Four cycles of controlled feedback took place before consensus on the questionnaire was reached. The constructed questionnaire was subsequently piloted on a cross-section of 20 medical students to assess method, design, and usability prior to fielding. It was created using the web-based tool SurveyMonkey (https://www.surveymonkey.com/). This prospective study was formulated according to the Checklist for Reporting Results of Internet E-Surveys (CHERRIES) statement (a validated tool for improving the quality of web-based surveys). ${ }^{5}$ The target population was medical students and junior doctors.

Facebook (https://www.facebook.com/) was selected as the tool for participant recruitment. On Facebook, medical schools typically have a "group" affiliated to them. For the student body, these act as informal posting boards and forums for both social and academic activity. We identified 6 UK medical schools with accessible groups. Four groups for hospital-affiliated junior doctors were also identified. The 
survey was uniformly distributed to these groups and was accompanied by the following phrasing "We would like to invite you to participate in our study on urology education in the UK. This is a short survey, which should take no more than 5 minutes to complete. All responses will be anonymous. The survey will be open for 10 days."

Prior to starting the survey, users were automatically directed to a full participant information page. Participation was voluntary and anonymous. Project details were outlined, such that all authors were satisfied that criteria for informed consent were met. Data were entered into a secure system and no personal information was collected. The survey consisted of 3 questions collecting demographic data, 1 closed format question, and 5 Likert questions. An additional 2 Likert questions were asked to the junior doctors (Appendix). Data were collected over a 10-day period. After 5 days, the survey was posted onto each group for a second and final time. Cookies were not used to give a unique user ID. Users were offered the chance to enter into a prize draw for a surgical textbook.

We excluded duplicate entries from the same Internet Protocol (IP) address and medical students and graduates from non-UK medical schools.

\section{Outcomes}

We assessed the following primary outcomes:

- Speciality preferences;

- Clinical exposure to urology;

- Perceived male dominance in urology;

- Consideration of urology as a career; and

- Confidence at male urethral catheterisation as an index procedure.

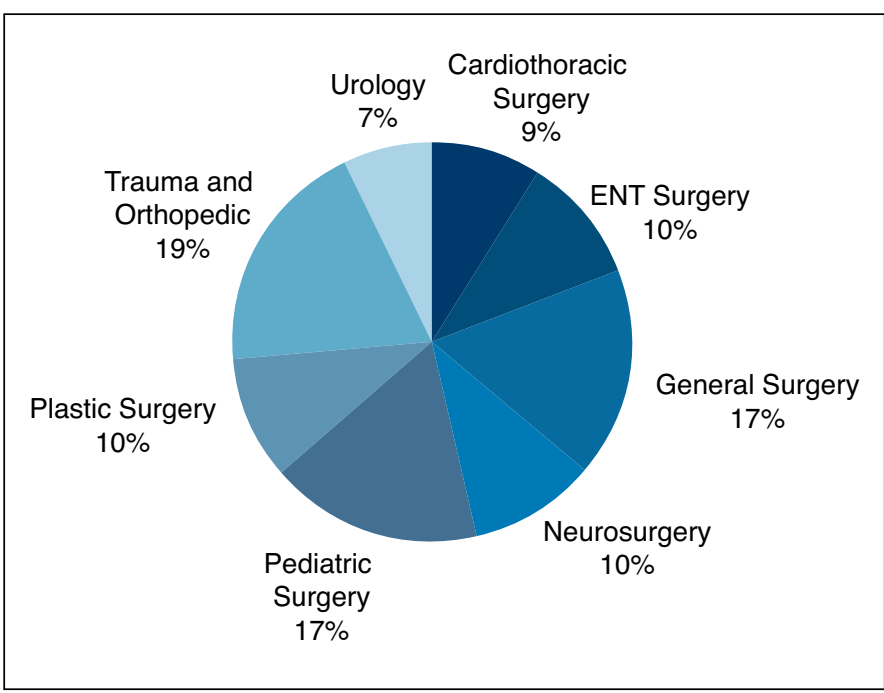

Fig. 1. Speciality preferences. ENT: ear, nose and throat.
We assessed the following secondary outcomes:

- Attitudes towards a workshop day in urology; and

- Confidence the junior doctor population have in making urology referrals and in the assessment of acute urological presentations.

\section{Statistical analysis}

Where results were compared between two independent samples, an independent samples z-test was used to test statistical significance of the differences. Differences indicated are significant at $95 \%$ confidence. Data analyzed by year of study was tested using the Kruskal-Wallis test. A $p$ value of less than 0.05 was considered significant. All calculations were performed with the software PSPP (version 0.8.4).

\section{Results}

A total of 478 surveys were completed (completion rate $96.7 \%$ ). A response rate of $87 \%$ was achieved and was calculated using the total number of members of the Facebook groups as the denominator. Of these, 412 were medical students and 66 were junior doctors. There were 197 males and 281 females.

\section{Primary outcomes}

Only $7 \%$ of the total sample indicated that urology would be the surgical specialty they would most likely to pursue as a career (males vs. females, $10 \%$ vs. $4 \%, p<0.01$, Fig. 1 ).

In comparison with medical students, significantly fewer junior doctors felt they had received good clinical exposure to urology $(29 \%$ vs. $44 \%, p=0.01$, Fig. 2$)$.

Junior doctors were significantly more likely than students to view urology as a male dominated specialty $(71 \%$ vs. $46 \%, p<0.01)$. The number of years studied had a signifi-

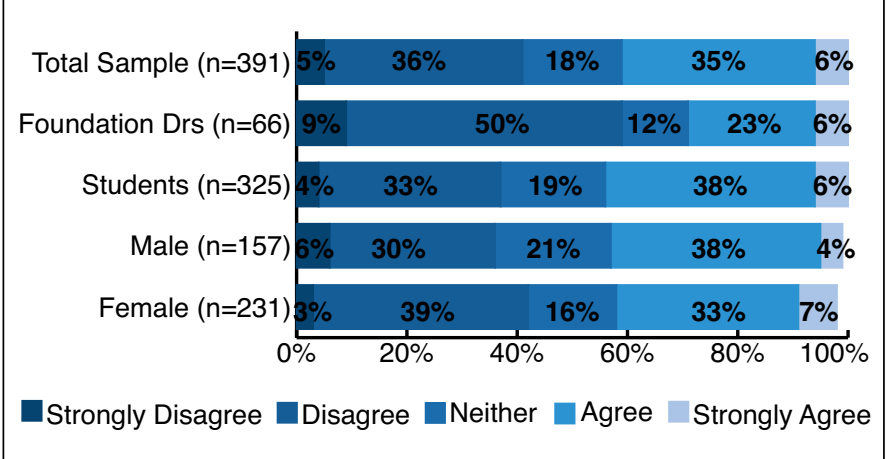

Fig. 2. Graphical display - Clinical exposure to urology. Foundation Drs refers to junior doctors. Question: I have received a good amount of clinical exposure to urology during my medical school training. 
cant effect on the perception of urology as a male-dominated specialty $(p<0.01)$. This perception increased with time spent studying medicine (Fig. 3).

Overall, only $15 \%$ of respondents either agreed or strongly agreed that they were considering a career in urology (Fig. 4). In total, $73 \%$ of junior doctors either disagreed or strongly disagreed, which was significantly higher than the proportion of students $(p=0.03)$. Across the total sample, females were significantly more likely than their male counterparts to give a negative response $(p<0.01)$.

Junior doctors were significantly more confident with male urethral catheterization as an index procedure than medical students ( $p<0.01$, Fig. 5). Across the total sample, men were more likely than women to feel confident with this technique $(p<0.01)$.

\section{Secondary outcomes}

There was a high level of agreement that a urology workshop day would be a good idea; $88 \%$ of survey respondents either agreed or strongly agreed with this statement.

For the additional questions presented to the junior doctors, $68 \%$ of the group would be confident making a urology referral, whereas they were less confident about assessing an acute urology admission with only $45 \%$ agreeing or strongly agreeing with this statement. More than 1 in 3 junior doctors would not feel confident assessing an acute urology admission.

\section{Discussion}

This study highlights a clinical exposure deficit in urology among medical students and junior doctors in the United Kingdom. Urology represented the least preferred surgical speciality from 8 choices and only a small proportion of respondents considered pursuing it as a career.

In the United Kingdom, the undergraduate medical program consists of a 5-year course, which leads to a Bachelor

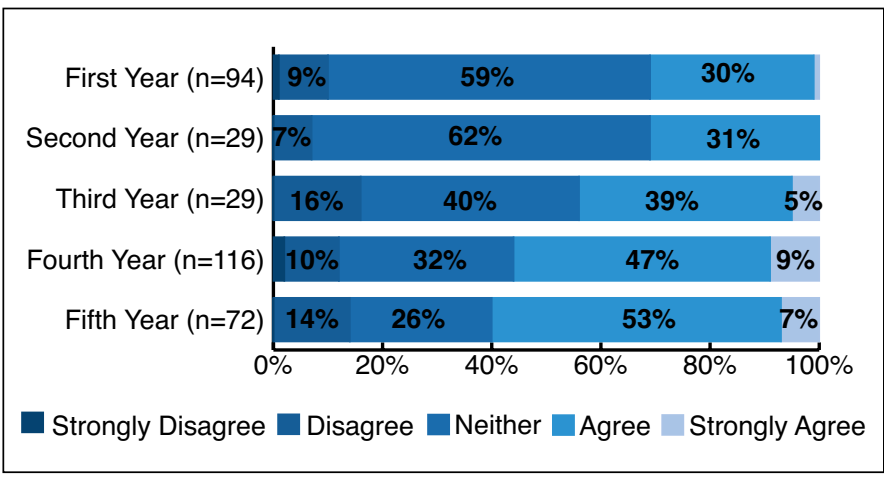

Fig. 3. Graphical display - Male dominance in urology. Foundation Drs refers to junior doctors. Question: Urology is a male dominated speciality. of Medicine and Surgery degree $(\mathrm{MBChB})$. The first 2 years traditionally include pre-clinical teaching with integrated hospital-based attachments. The final 3 years are undertaken in the clinical setting as the student rotates through fixed clerkships in the core medical and surgical specialities. Upon graduation, junior doctors must complete 2 years of basic training in the hospital setting, termed "Foundation Years 1 and 2." During this time, individuals gain full registration with the General Medical Council (GMC), an independent body, which governs the standards physicians must meet in order to practice. After this period of so called "Foundation Training," junior doctors wishing to pursue a career in surgery must undergo 2 years of "Core Surgery" before being eligible to apply to higher surgical training posts in their chosen speciality.

In 2010, the ratio of applicants to higher surgical training posts in urology was $1.4: 1$, whereas for plastic surgery and pediatric surgery it was $7: 1$ and $3.7: 1$, respectively. Overall, despite urology being oversubscribed, it had the least number of applicants per post for any of the surgical specialities. Kerfoot and colleagues argued that it is critical to attract the brightest to fuel the advancement of urology. ${ }^{6}$ The authors surveyed applicants to a local urology program in Boston, Massachussetts. They found that the key negative determinants were the perceived repetitive nature of the pathology and the high demands of a surgical residency.

The British Association of Urological Surgeons (BAUS) has previously highlighted the difficulties in delivering urology teaching in the context of the changes summarised in the GMC document "Tomorrow's doctors." This revealed the paradigm shift in the undergraduate medical curricula towards student selected projects and primary care placements. ${ }^{7.8}$ Malde and colleagues reported that $26.6 \%$ of UK medical students in their study group had no undergraduate urology attachment throughout their clinical clerkship. Moreover, 30.5\% completed a compulsory attachment, however this lasted for 1 week only. ${ }^{9}$ Granular data on the formal pre-clinical teaching allocated to urology across

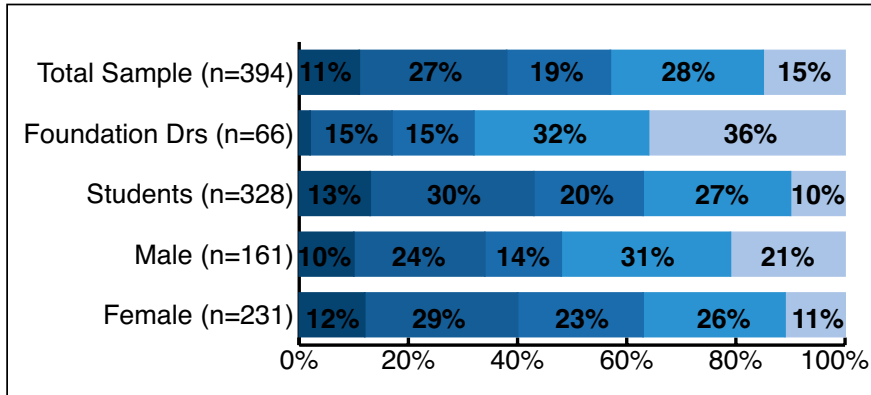

Strongly Disagree $\square$ Disagree $\square$ Neither $\square$ Agree $\square$ Strongly Agree

Fig. 4. Graphical display - Urology as a career choice. Foundation Drs refers to junior doctors. Question: I am considering a career in urology. 
Jones et al.

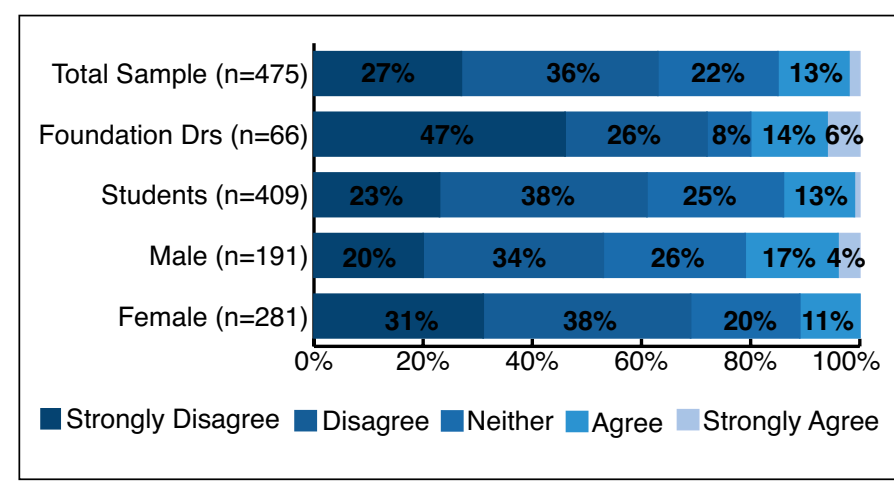

Fig. 5. Graphical display -Confidence at male catheterization. Foundation Drs refers to junior doctors. Question: I feel confident at the technique of male catheterization.

different UK medical schools is limited and therefore it is difficult to draw accurate comparisons. At our institution (Dundee University School of Medicine), 2 mandatory weeks of lecture-based teaching are devoted to urology in the pre-clinical syllabus. The option of a 4-week, student selected project is also available.

The exposure deficit appears to be a similar cause for concern in the United States. In a survey of US medical school directors, $65 \%$ agreed it was possible to complete their program without clinical exposure to urology. ${ }^{2}$ Kutikov and colleagues surveyed applicants to the US residency program and concluded that compulsory clinical exposure and length of clinical attachments in urology strongly correlated with a greater number of medical students enrolling in this speciality. ${ }^{10}$ In Canada, Melnyk and colleagues reviewed the trends in matching to urology residency and found that while the number of positions available had doubled, the number of applicants remained unchanged. ${ }^{11}$

Urology workshops are not routinely incorporated into the learning program delivered by any UK medical school. It may therefore be essential to incorporate such didactic interventions beyond regular teaching, such as in a simulation lab setting, to improve the competency of students at carrying out core skills. This would adhere to the pressures of working time directives and help compensate for the short duration students spend in urology attachments. Interestingly, Hoag and colleagues reported that Canadian medical students learning at smaller academic units were significantly more satisfied with their urology teaching and also more comfortable at skills, such as ultrasound bladder scanning. ${ }^{12}$

The reported gaps in knowledge among juniors can have a knock on effect as the individual progresses in their chosen career. ${ }^{13}$ This is particularly the case in primary care, a discipline many students pursue in both the UK and Canada. ${ }^{14}$ Wei and colleagues used the management of benign prostatic hyperplasia (BPH) to demonstrate marked differences in practice patterns of urologists compared with primary care physicians (PCPs). ${ }^{15}$ Urologists were twice as likely to prescribe BPH medical therapy over watchful waiting compared to PCPs. When scrutinizing the medication choices this latter group made, the authors felt their decisions indicated less awareness to relevant evidence based research. Refresher workshops tailored to the requirements of PCPs could also improve the management of urological conditions in the primary care setting.

The limitations of this study were its small sample size and the method of survey sampling employed, which has the potential to introduce an element of self-selection bias. A subsequent, larger scale study could be carried out to improve the external validity of these findings. Given the paucity of data on undergraduate programs across the UK, future studies could compare and evaluate the urology curricula delivered by UK medical schools.

\section{Conclusions}

This study provides a contemporary snapshot of current opinion among UK medical students and junior doctors. The current program of urology education in the United Kingdom does not lead to satisfactory preparedness. In failing to inspire, the current program fails to secure future applicants to this surgical field and equip future PCPs.

Competing interests: The authors all declare no competing financial or personal interests.

This paper has been peer-reviewed.

\section{References}

1. Slaughenhoupt $B$, Ogunyemi 0 , Giannopoulos $M$, et al. An update on the current status of medical student urology education in the United States. Urology 2014;84:743-7. http://dx.doi.org/10.1016/j. urology.2014.06.003

2. Loughlin KR. The current status of medical student urological education in the United States. I Urol 2008;179:1087-90. http://dx.doi.org/10.1016/i.juro.2007.10.068

3. Forsythe RO, Eylert MF. Medical students and foundation doctors need more exposure to basic urology. Bulletin of The Royal College of Surgeons of England 2014;7:240-3(4).

4. Miller DC, Saigal CS, Litwin MS. The demographic burden of urologic diseases in America. Urol Clin North Am 2009;36:11-27;v. http://dx.doi.org/10.1016/j.ucl.2008.08.004

5. Eysenbach $G$. Improving the quality of web surveys: The checklist for reporting results of internet e-surveys. J Med Internet Res 2004;6:e34. http://dx.doi.org/10.2196/imir.6.3.e34

6. Kerfoot BP, Nabha KS, Masser BA, et al. What makes a medical student avoid or enter a career in uroogy? Results of an international survey. J Urol 2005;174:1953-7. http://dx.doi.org/10.1097/01. ju.0000177462.61257.4e

7. British Association of Urology Surgeons. BAUS Undergraduate Syllabus for Urology. March 2012. http:// www.baus.org.uk/_userfiles/pages/files/professionals/education/Undergraduate\%20Syllabus.pdf. Accessed July 30, 2015.

8. General Medical Council. Tomorrow's doctors. London: General Medical Council, 2013. http://www. gmc-uk.org/publications/undergraduate_education_publications.asp. Accessed July 30, 2015.

9. Malde S, Shrotri N. Undergraduate urology in the UK: Does it prepare doctors adequately? British Journal of Medical and Surgical Urology 2012;5:20-7. http://dx.doi.org/10.1016/i.bjmsu.2011.09.001 
10. Kutikov A, Bonslaver J, Casey JT, et al. The gatekeeper disparity - why do some medical schools send more medical students into urology? J Urol 2011;185:647-52. http://dx.doi.org/10.1016/i. juro.2010.09.113

11. Melnyk M, Nelson H, Mickelson J, et al. Trends in matching to urology residency in Canada: Are we becoming noncompetitive? Journal of Surgical Education 2013;70:537-43. http://dx.doi.org/10.1016/i. jsurg. 2013.02 .006

12. Hoag NA, Hamidizadeh R, Macneily AE. Undergraduate exposure to urology: Impact of the distributed model of medical education in British Columbia. Can Urol Assoc J 2011:1-6.

13. Mishail A, Shahsavari $M$, Kim J, et al. Deficits in urological knowledge among medical students and primary care providers: Potential for impact on urological care. J Urol 2008;180:2140-7. http://dx.doi. org/10.1016/i.juro.2008.07.043
14. Canadian Resident Matching Service. http://www.carms.ca. Accessed May 28, 2015.

15. Wei JT, Miner MM, Steers WD, et al. Benign prostatic hyperplasia evaluation and management by urologists and primary care physicians: Practice patterns from the observational BPH registry. J Urol 2011;186:971. http://dx.doi.org/10.1016/i.juro.2011.04.081

Correspondence: Mr. Patrick Jones, Ninewells Hospital and Medical School, University of Dundee, Scotland, UK, DDI 9SY; patrick.jones1@nhs.net

\section{Appendix 1. Survey questions.}

\section{Question 1.}

Sex:

$\bigcirc \quad$ Male

Female

Question 2. Medical school attended:

\section{Question 3. Year of study:}

Year 1
$\bigcirc$
$\bigcirc$
$\bigcirc$
Year 2
Year 3
Year 4
Year 5

Question 4.

Which speciality would you most like to pursue a career in?

Please select 1 from the following options:

$\begin{array}{ll}\text { O } & \text { Cardiothoracic Surgery } \\ \bigcirc & \text { ENT surgery } \\ \bigcirc & \text { General Surgery } \\ \bigcirc & \text { Neurosurgery } \\ \bigcirc & \text { Paediatric Surgery } \\ \bigcirc & \text { Plastic Surgery } \\ \bigcirc & \text { Urauma and Orthopaedics }\end{array}$

Question 5.

I have received a good amount of clinical exposure to urology during my medical school training
1. Strongly disagree
2. Disagree
3. Neither agree nor disagree
4. Agree
5. Strongly agree
O
$\mathrm{O}$
$\mathrm{O}$
O
$\bigcirc$

Question 6.

Urology is a male dominated speciality
1. Strongly disagree
2. Disagree
3. Neither agree nor disagree
4. Agree
5. Strongly agree
$\mathrm{O}$
O
O
O
$\bigcirc$

Question 7.

I am considering a career in urology
1. Strongly disagree
2. Disagree
$\mathrm{O}$
O

4. Agree

5. Strongly agree

O

O

O

Question 8.

I feel confident at the technique of male catheterisation
1. Strongly disagree
2. Disagree
O
O

3. Neither agree nor disagree

4. Agree

5. Strongly agree

$\bigcirc$

O 
Jones et al.

\section{Appendix 1. Survey questions (cont'd). Additional questions for Foundation doctors}

Question 9.

A workshop day in urology would be a good idea to help me learn core topics and examination skills
1. Strongly disagree
2. Disagree
3. Neither agree nor disagree
4. Agree
5. Strongly agree
O
O
$\mathrm{O}$
O
$\mathrm{O}$

Question 10.

I feel confident making a urology referral to the senior on call
1. Strongly disagree
2. Disagree
3. Neither agree nor disagree
4. Agree
5. Strongly agree
O
O
○
O
O

Question 11.

I feel confident assessing an acute urology admission
1. Strongly disagree
2. Disagree
3. Neither agree nor disagree
4. Agree
5. Strongly agree
O
O
$\bigcirc$
$\bigcirc$
$\bigcirc$ 